\title{
EFFECT OF GLYCEMIC STATE IN RATS SUBMITTED TO STATUS EPILEPTICUS DURING DEVELOPMENT
}

\author{
Joselita F.C. Santiago', Fatima F. Carvalho', Sandra R. Perosa', \\ Marcelo R. Siliano', José Walber M.C. Cruz², Maria José S. Fernandes ${ }^{3}$, \\ Esper A. Cavalheiro ${ }^{4}$, Débora Amado 3 , Maria da Graça Naffah-Mazzacoratti ${ }^{5}$
}

\begin{abstract}
The effect of glycemic state on status epilepticus (SE) development was studied in animals of diffe rent ages, submitted to pilocarpine model of epilepsy. Groups: I- Rats with 9-day-old (P9): IA. Submitted to 1SE; IB. Saline-treated; IC. Induced- hyperglycemia; ID. Induced- hyperglycemia+SE; II- Rats submitted to th ree consecutive episodes of SE at P7, P8 and P9; III- Rats submitted to 1SE at P17; IV- Rats submitted to 1SE at P21. Hippocampal cell death and the expression of glucose transporter GLUT3 were analyzed in group I. The results demonstrated normoglycemia in the groups IA, IB and II, hypoglycemia in group III and hyperglycemia in group IV, showing that the glycemia during SE is age dependent. Induced hyperglycemia during SE in P9 protected the hippocampal neurons from death and both groups IC and ID presented increased GLUT3 expression, showing high glucose consumption by the hippocampus.
\end{abstract}

KEY WORDS: status epilepticus, pilocarpine, glycemia, hippocampus, glucose transporter 3.

\begin{abstract}
Efeito do estado glicêmico em ratos submetidos ao status epilepticus durante o desenvolvimento

RESUMO - O efeito do estado glicêmico sobre o desenvolvimento do status epilepticus (SE) foi estudado em animais de diferentes idades, submetidos ao modelo de epilepsia por pilocarpina. Grupos: I- Ratos com nove dias (P9): IA- Submetidos a 1SE; IB- Tratados com salina; IC- Hiperglicemia induzida; ID- Hiperglicemia induzida+SE; II- Ratos submetidos a 3 episódios consecutivos de SE em P7, P8 e P9; III- Ratos submetidos a 1SE em P17; IV- Ratos submetidos a 1SE em P21. Foram analisados no grupo I a morte celular hipocampal e a expressão do transportador de glicose GLUT3. Os resultados mostraram haver normoglicemia nos grupos IA, IB e II, hipoglicemia no grupo III e hiperglicemia no grupo IV, sendo a glicemia durante o SE, idade dependente. A hiperglicemia induzida durante o SE em P9 protegeu neurônios hipocampais e os grupos IC e ID apresentaram expressão aumentada de GLUT3, mostrando aumento no consumo de glicose pelo hipocampo.
\end{abstract}

PALAVRAS-CHAVE: status epilepticus, pilocarpina, glicemia, hipocampo, transportador de glicose 3.

Status epilepticus (SE) induced by high doses of pilocarpine in rats has received special attention, since this injury drive on a type of epilepsy in rodents, which reproduce the main clinical and neuropathological features of human temporal lobe epilepsy. When developed in adult animals, this experimental model is able to produce long-lasting SE (acute period, 12h), a seizure-free period (silent period, 14 days) and spontaneous recurrent seizures (chronic period), which a re associated to extensive cell loss in several brain structures and mossy fiber sprouting in the hippocampal formation ${ }^{1-3}$. The consequences of pilocarpine-induced SE are age dependent. When SE is induced in
7 (P7) to 11 (P11) days-old rats no neuronal damage or spontaneous recurrent seizures has been described $^{4}$. In addition, when SE is induced between 18 and 24 days, the occurrence of epilepsy-related damage in the brain is less extensive than in adult rats ${ }^{4}$.

The occurrence of SE during the perinatal period or early childhood cause cognitive impairment ${ }^{5,6}$. However, it remains under controversy whether this injury is responsible for epilepsy during the adulthood. According to a recent work ${ }^{6}$ the administration of LiCl-pilocarpine to $\mathrm{P} 12$ and $\mathrm{P} 25$ rats was able to induce impaired memory and ictal activity in adult animals. In P12 group, the EEG recorded 3-4 moths

Disciplina de Neurologia Experimental, Departamento de Neurologia e Neurociru rgia, Universidade Federal de São Paulo, São Paulo SP, Brazil (UNIFESP/EPM): 'Aluno de pós-graduação UNIFESP/EPM; ${ }^{2}$ PhD, Professor da Disciplina de Imuno-histoquímica e Inflamação, Faculdade de Medicina da Universidade de São Paulo; ${ }^{3} \mathrm{PhD}$, Professor Adjunto da Disciplina de Neurologia Experimental UNIFESP/EPM; ${ }^{4} \mathrm{PhD}$, Professor Titular da Disciplina de Neurologia Experimental UNIFESP/EPM; ${ }^{5} \mathrm{PhD}$, Professora Livre Docente da Disciplina de Neurologia Experimental/Bioquímica, UNIFESP/EPM e Instituto do Coração (INCOR), Faculdade de Medicina, Divisão de Pesquisa, Universidade de São Paulo (USP). Supported by FAPESP, CNPq, FADA, CAPES. 
after SE showed $75 \%$ of animals presenting short periods (less than $10 \mathrm{sec}$ ) of hippocampal sharp waves that were bilaterally synchronous and did not spread to the cortex. Motor convulsions were never observed in these rats. In addition, all P25 animals exhibited epileptiform EEG activity and $60 \%$ of electrographic seizures were associated with clonic seizures at stage 3-5, according to Racine's scale ${ }^{7}$. On the other hand, several authors have reported high brain glucose consumption during SE. According to Fernandes 8 , the hypermetabolism occur in areas associated with brain damage in older animals. In P10 and P21 rats the sustained major metabolic activation lead to a variable extent of damage, which increases with animal age. Previous data of our group showed the presence of hyperglycemia during the first three hours, after the SE onset, in adult rats. Thus, this hyperglycemia could be involved in the brain damage, observed in these animals after pilocarpine-induced SE.

Trying to correlate hyperglycemia, neuronal loss and SE the aim of the present work was to evaluate the effect of induced-hyperglycemia on neuronal death in P9 rats, submitted to SE as well as the expression of brain glucose transporter (GLUT3) in these animals. Since older rats show neuronal death in several brain regions, we also analyzed the blood glucose levels in animals of different ages, submitted to SE.

\section{METHOD}

The experimental protocol was approved by the Ethical Committee of Universidade Federal de São Paulo and all efforts were done to minimize animal suffering.

Male Wistar rats, born and maintained under controlled condition, using standard light/dark cycle of $12 \mathrm{~h}$, and rat chow pellets and water ad libitum were employed. The colony room had a temperature of $21 \pm 2^{\circ} \mathrm{C}$. The rats were mate in our laboratories and the day of birth was considered as day zero (P0). The pups were housed with their mother in appropriate cages until experimentation. For induction of SE subjects were selected randomly from the appropriate cage. At P2 the males were selected and each hatch was composed by 8 rats, plus the mother.

Procedures - Male Wistar rat received pilocarpine using doses ranging from 180 to $380 \mathrm{mg} / \mathrm{kg}$ (ip). The different concentrations of pilocarpine necessary to induce SE were $p$ reviously described by our group, for animals in development $^{9}$. P21 rats received $1 \mathrm{mg} / \mathrm{kg}$ of methyl-scopolamine, $30 \mathrm{~min}$ before pilocarpine administration, to reduce peripheral effects. Control P21 animals received also methyl-scopolamine and control animals of all ages received an equivalent volume of saline instead pilocarpine. Young animals (less than P17) did not receive methyl-scopolamine since at this age this drug can cross the blood-brain barrier, which is not completely developed, blocking SE induction (our data not published).
$G$ roup I. Animals submitted to SE at P9 - IA) These rats we re submitted to one episode of status epilepticus (SE) receiving pilocarpine (380 $\mathrm{mg} / \mathrm{kg}$-ip) at $P 9(n=6)$; IB) Similar procedurewas done with control animals (P9), which received saline instead pilocarpine $(n=6)$; IC) Hyperglycemia was induced in P9 animals, through glucose administration, according to protocol described by Reeves ${ }^{10}$. The first dose ( $0.2 \mathrm{~mL}$ at $50 \%$-ip) was administered $5 \mathrm{~min}$ after pilocarpine injection. The second $(0.15 \mathrm{~mL}$ at $25 \%$-ip) one hour late and the third ( $0.2 \mathrm{~mL}$ at $50 \%$-ip) tree hours late; ID) Hyperglycemia associated with SE induction was obtained after pilocarpine administration in hyperglycemic P9 animals, induced according Reeves ${ }^{10}$ protocol.

The level of blood glucose was measured at 0, 90, 180 and $360 \mathrm{~min}$. The animals from group I were analyzed by th ree diffe rent parameters: blood glucose level, hippocampal cell death (Nissl staining) and hippocampal distribution of glucose transporter (GLUT3-Immunohistochemistry). In the rats from groups II, III and IV we only analyzed the blood glucose level.

Group II. Animals submitted to 3SE at P7, P8 and P9 IIA) These rats were submitted to three consecutive episodes of status epilepticus (3SE) receiving one injection/day of pilocarpine (380 mg/kg) at P7, P8 and P9 $(\mathrm{n}=8)$; IIB) Similar procedure was done with control animals, which received saline instead pilocarpine $(n=8)$. The level of blood glucose was measured at $0,30,90,120,180$ and $360 \mathrm{~min}$ in all rats.

Group III. Animals submitted to 1 SE at P17 - IIIA) Animals $(n=8)$ were submitted to pilocarpine-induced SE (225 mg/kg); IIIB) Similar procedurewas done with control animals, which received saline instead pilocarpine $(n=8)$ and the level of blood glucose was measured at $0,30,90$, 120,180 and $360 \mathrm{~min}$ in all rats.

Group IV. Animals submitted to 1 SE at P21 - IVA) Animals $(n=8)$ was submitted to pilocarpine-induced SE (180 $\mathrm{mg} / \mathrm{kg}$ pilocarpine plus $1 \mathrm{mg} / \mathrm{kg}$ methyl-scopolamine); IVB) Similar procedure was done with control animals, which received saline instead pilocarpine $(n=8)$ and the level of blood glucose was measured at $0,30,90,120,180$ and 360 $\min$ in all rats.

Blood glucose level - The level of glucose was measured at $0,30,90,120,180$ and $360 \mathrm{~min}$ in the blood of all animals from all groups using the Advantage monitor (Roche). For this purpose, one drop of blood was withdrawn from animals' tail. Rats presenting glucose blood values equal or superior of $6.16 \mathrm{~m} \mathrm{~mol} / \mathrm{L}$ were considered hyperglycemic. Those rats presenting glucose level equal or inferior of $3.92 \mathrm{mmol} / \mathrm{L}$ were considered hypoglycemic and normoglycemic those animals presenting between 3.92-6.16 $\mathrm{mmol} / \mathrm{L}$.

Immunohistochemistry-After $6 \mathrm{~h}$ of induced-SE or in control animals the rats were anaesthetized and perfused transcardally with paraformaldehyde (Labsynth) $(15 \mathrm{~mL}$ at $1 \%)$, followed by paraformaldehyde ( $40 \mathrm{~mL}$ at $4 \%$ ). The 
brains were removed immediately after perfusion and postfixed in paraformaldehyde (4\%). Brains were sectioned in $50 \mu \mathrm{m}$ thicknesses using vibratome, collected, and washed with PBS ( $\mathrm{pH}$ 7.4). All sections were treated with $3 \% \mathrm{H}_{2} \mathrm{O}_{2}$ in PBS to quench endogenous per oxidase and then incubated for $2 \mathrm{~h}$ in phosphate saline buffer (PBS) containing $0.1 \%$ Triton X-100 (Merck) and milk 5\%. After this, the sections were incubated for $16 \mathrm{~h}$ at $4^{\circ} \mathrm{C}$ in primary antibody (mouse anti-GLUT3 1:10 (Santa Cruz) in milk 1\%. Following th re washes in PBS, the sections were incubated with the secondary antibody byotinilated (anti-mouse IgG pero $\mathrm{xi}$ dase conjugate, 1:200, Sigma) during $2 \mathrm{~h}$. Immunodetection was performed using the Vectastain $A B C$ Elite Kit (Vector Burlingame, CA, USA) during $90 \mathrm{~min}$ and the complex antigen-antibody was visualized using diaminobenzidine (DABAbott). Tissue sections were mounted on glass slides. The material was studied with a microscope using bright-field illumination. To study the antibody specificity the primary antibody was replaced by blocking solution and the immunohistochemistrywas performed as described. The quantification of stained cell was performed in all groups.

Hippocampal cell density - After $6 \mathrm{~h}$ of induced SE or in control animals the rats were anaesthetized and perfus ed transcardially with paraformaldehyde (Labsynth) $(15 \mathrm{~mL}$ at $1 \%$ ) followed by paraformaldehyde ( $40 \mathrm{~mL}$ at $4 \%$ ). The brains were removed immediately fixed, dehydrated, immersed in paraffin, sliced at $12 \mu \mathrm{m}$ and stained with cresyl violet. After Nissl staining the cells present in the hippocampal formation of animals from group I were counted using an image program (Image pro-plus version 4, developed by Media Cybernetics). Specific regions such as CA1, CA3, dentate gyrus and hilus were selected and the cell density was analyzed. Control hippocampi were used as $100 \%$ of cell density in each selected region.

Data analysis - The results were analyzed using ANOVA, followed by Tukey-Kramer pos-test. Values of $p<0.05$ were considered significant.

\section{RESULTS}

Blood glucose level - The blood glucose levels, followed during 360 min of all animals from group I. Animals in P9 presented normal level of glucose blood during $6 \mathrm{~h}$ of SE (group IA; IB). Animals from $g$ roup IC and ID presented hyperglycemia from 90 to 360 min after the initial procedure, showing that the induction of hyperglycemia was efficient.

The glycemia of animals submitted to three consecutives SE at P7, P8, P9 (group II) were not modified, when compared with saline-treated animals. Animals submitted to SE at P17 (group III) showed hypoglycemia at 90, 120, 180 and $360 \mathrm{~min}$, when compared with control animals. In contrast, animals at P21 (group IV) showed a hyperglycemia peak during the first $30 \mathrm{~min}$ of induced-SE. These results showed that in rats, during early stages of development, the blood glucose level was not modified by pilocarpine-induced SE. Older animals such as those in P21 already showed a hyperglycemic peak, resembling that pattern observed in adult rats. These data are summarized in Table 1.

Table 1. Glycemic rates, expressed as mmol/L represent mean $\pm S D$.

\begin{tabular}{|c|c|c|c|c|c|c|c|}
\hline & \multirow[t]{2}{*}{ Groups } & \multicolumn{6}{|c|}{ Glycemia } \\
\hline & & 0 minutes & 30 minutes & 90 minutes & 120 minutes & 180 minutes & 360 minutes \\
\hline \multirow{4}{*}{ Group I } & P9 SE & $5.71 \pm 14.79$ & - & $4.54 \pm 35.92$ & - & $4.59 \pm 35.49$ & $4.77 \pm 28.92$ \\
\hline & P9 Saline & $5.90 \pm 16.35$ & - & $5.30 \pm 15.99$ & - & $5.24 \pm 17.17$ & $4.74 \pm 17.57$ \\
\hline & P9 Hyperglycemia & $5.61 \pm 4.62$ & - & $33.04 \pm 13.98 * * *$ & - & $24.30 \pm 29.46 * * *$ & $26.47 \pm 25.40 * * *$ \\
\hline & P9 SE+Hyperglycemia & $5.65 \pm 5.93$ & - & $20.63 \pm 25.23 * * *$ & - & $22.72 \pm 25.88 * * *$ & $17.64 \pm 32.74 * * *$ \\
\hline \multirow[t]{6}{*}{ Group II } & $\mathrm{P} 71^{\circ} \mathrm{SE}$ & $5.55 \pm 14.10$ & $7.18 \pm 8.88$ & $7.80 \pm 21.47$ & $7.23 \pm 20.90$ & $6.76 \pm 20.08$ & $5.98 \pm 17.17$ \\
\hline & P7 Saline & $5.65 \pm 5.60$ & $5.50 \pm 13.45$ & $5.45 \pm 18.67$ & $5.27 \pm 10.22$ & $5.05 \pm 6.19$ & $4.87 \pm 5.79$ \\
\hline & P8 $2^{\circ} \mathrm{SE}$ & $5.12 \pm 2.28$ & $5.52 \pm 14.20$ & $6.29 \pm 14.52$ & $5.89 \pm 19.80$ & $5.50 \pm 28.93$ & $5.26 \pm 5.60$ \\
\hline & P8 Saline & $5.81 \pm 8.17$ & $5.41 \pm 5.80$ & $5.33 \pm 12.68$ & $5.10 \pm 6.72$ & $4.96 \pm 14.20$ & $4.76 \pm 5.80$ \\
\hline & P9 $3^{\circ} \mathrm{SE}$ & $5.82 \pm 7.12$ & $5.90 \pm 17.37$ & $5.16 \pm 19.64$ & $5.95 \pm 5.12$ & $5.25 \pm 5.83$ & $6.00 \pm 12.97$ \\
\hline & P9 Saline & $6.13 \pm 8.32$ & $5.69 \pm 13.14$ & $5.46 \pm 18.92$ & $4.93 \pm 15.92$ & $4.71 \pm 12.17$ & $4.54 \pm 15.20$ \\
\hline \multirow[t]{2}{*}{ Group III } & P17 SE & $4.85 \pm 10.29$ & $5.33 \pm 2.68$ & $2.48 \pm 30.65 * * *$ & $1.53 \pm 7.91 * * *$ & $1.54 \pm 12.41 * * *$ & $3.01 \pm 22.70 *$ \\
\hline & P17 Saline & $5.07 \pm 9.80$ & $4.74 \pm 11.70$ & $4.45 \pm 15.23$ & $4.49 \pm 14.22$ & $4.29 \pm 16.40$ & $4.26 \pm 18.20$ \\
\hline \multirow[t]{2}{*}{ Group IV } & P21 SE & $5.15 \pm 6.76$ & $9.69 \pm 21.30 * * *$ & $6.78 \pm 18.92$ & $4.22 \pm 29.56$ & $4.18 \pm 4.16$ & $5.20 \pm 20.41$ \\
\hline & P21 Saline & $5.73 \pm 9.79$ & $5.13 \pm 12.78$ & $5.01 \pm 8.62$ & $4.73 \pm 16.44$ & $4.46 \pm 14.06$ & $4.37 \pm 12.00$ \\
\hline
\end{tabular}

Groups $n=8$. ANOVA followed by Tukey-Kramer test $(* p<0.05)(* * * p<0.001)$. 


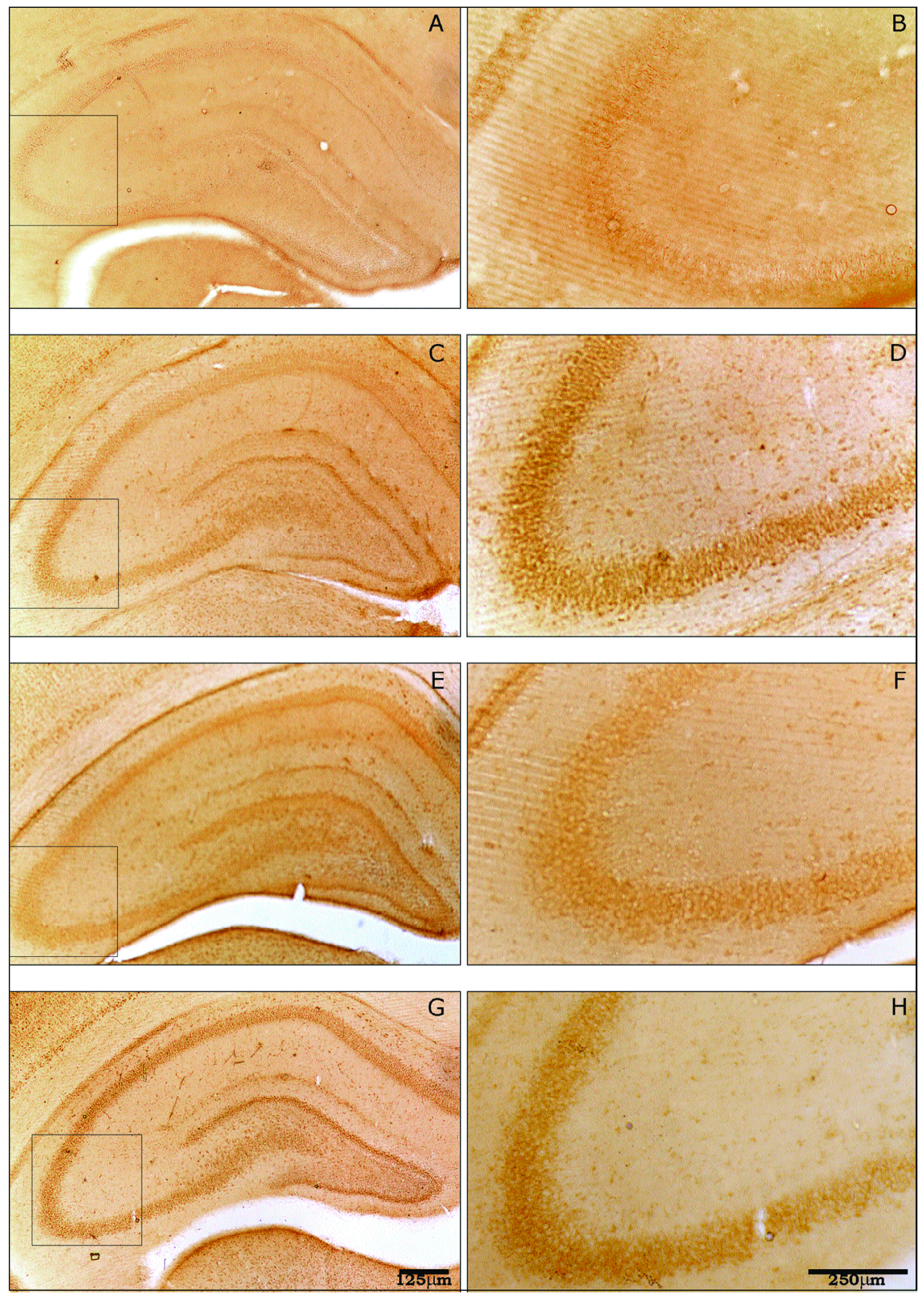

Fig 1. Photomicrograph of GLUT3 immunostaining in the hippocampal formation. The figures $B, D, F$ and $H$ show details in 100X magnifications of CA3 region. Saline-treated group $(A, B)$; SE group (C, D); hyper glycemia group $(E, F)$; SE+hyperglycemia group $(G, H)$.

GLUT3 immunostaining - The quantitative analysis of GLUT3 immunoreactivity in animals from group I showed modification in the expression of this glucose transporter. Slices from saline-treated animals p resented a weak staining in all hippocampal formation (Figs 1A, 1B, 2A, 2B and 3). Rats submitted to SE p resented increased immureactivity against GLUT3, when compared with control group. This increased 


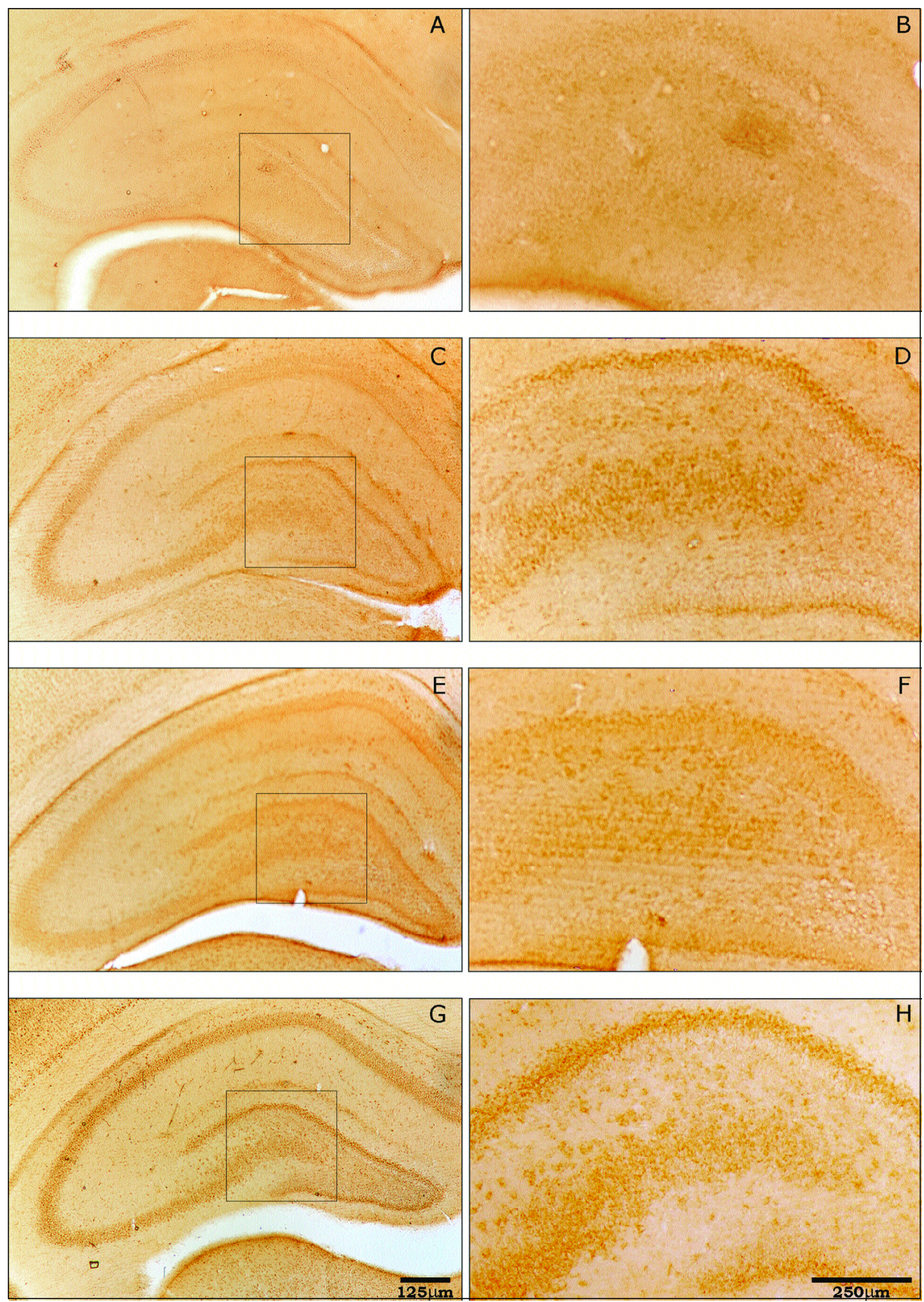

Fig 2. Photomicrograph of GLUT3 immunostaining in the hippocampal formation. The figures $B, D, F$ and $H$ show details in $100 X$ magnification of dentade gyrus hilus region. Saline-treated group $(A, B)$; SE gro up $(C, D)$; hyperglycemia group $(E, F)$; $S E+$ hyperglycemia group $(G, H)$.

expression was visualized mainly in CA1, CA3, hilus and dentate gyrus (Figs 1C, 1D, 2C, 2D and 3). Animals submitted only to hyperglycemia showed moderated immunoreactivity against GLUT3, which was more intense when compared with saline-treated animals and less stained when compared with pilocarpineinduced SE group (Figs 1E, 1F,2E, 2F and 3). Rats submitted to SE plus hyperglycemia showed intense ex- 


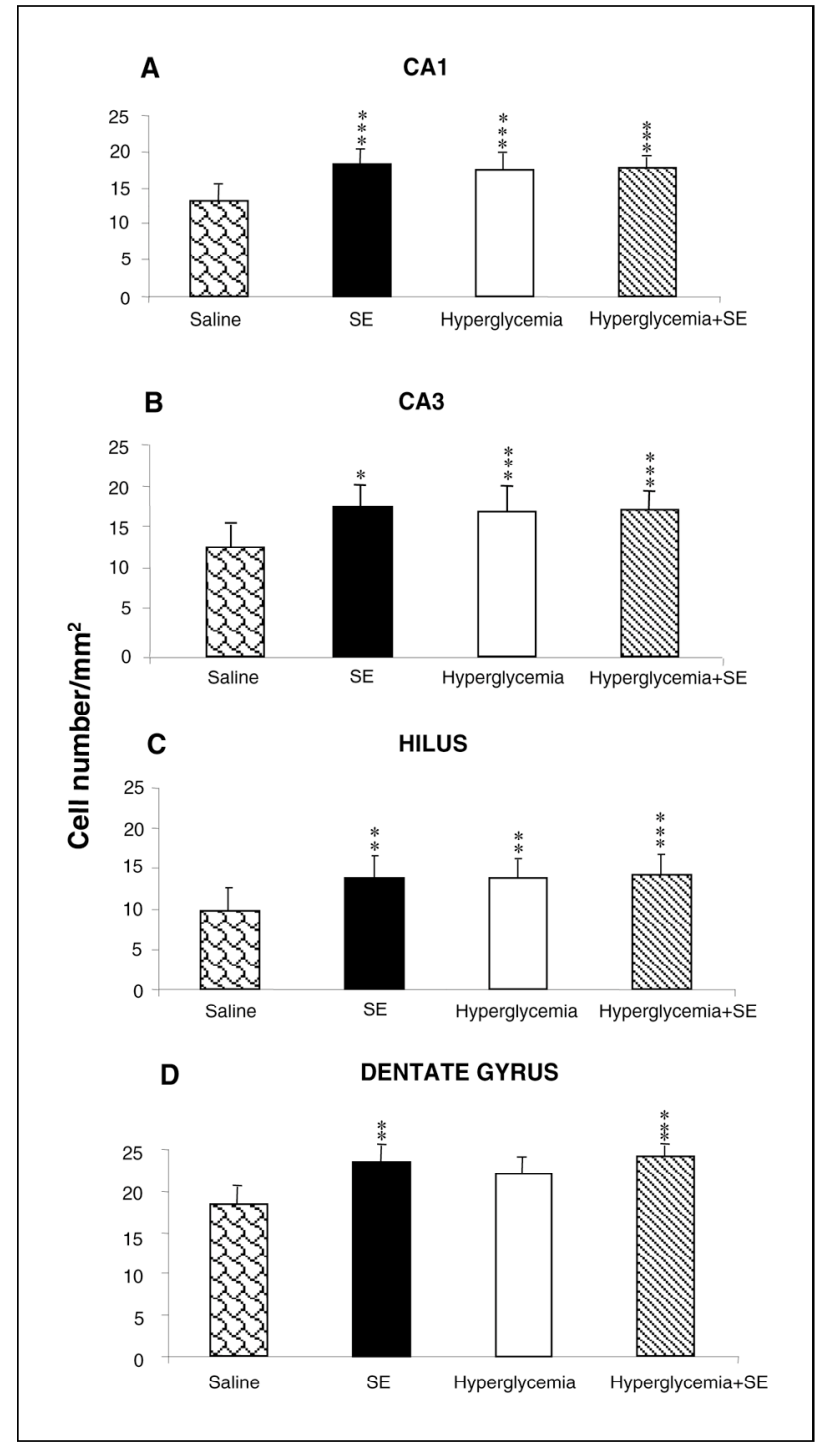

Fig 3. Number of cells in the hipocampus. Saline- animals salinetreated; SE- animals submitted to SE; Hyperglycemia- animals submitted to hyperglycemia; SE+hyperglycemia-animals sub mitted to SE plus hyperglycemia. A) CA1 region; B) CA3 region; $C)$ dentate gyrus hilus region; $D$ ) dentate gyrus region. Groups $(n=8)$ of male Wistar rats 9-day old (P9). The data are expressed as percentge of Saline group. ANOVA followed by Tukey-Kra mer test $(* p<0,05)(* * p<0,01)(* * *<0,001)$.

pression of GLUT3. This staining could be visualized in all hippocampal formation (Figs 1G, 1H, 2G, 2H and 3 ) in similar regions to that found in SE group. All quantitative results are shown in Figure 3.

Cell density - The cell density analyzed by Nissl staining in all animals from group I showed that animals submitted to SE at P9 presented cell death in CA3 and hilus regions. Animals submitted only to hyp e rglycemia also showed cell loss in the hilus region of hippocampal formation. Rats submitted to SE plus

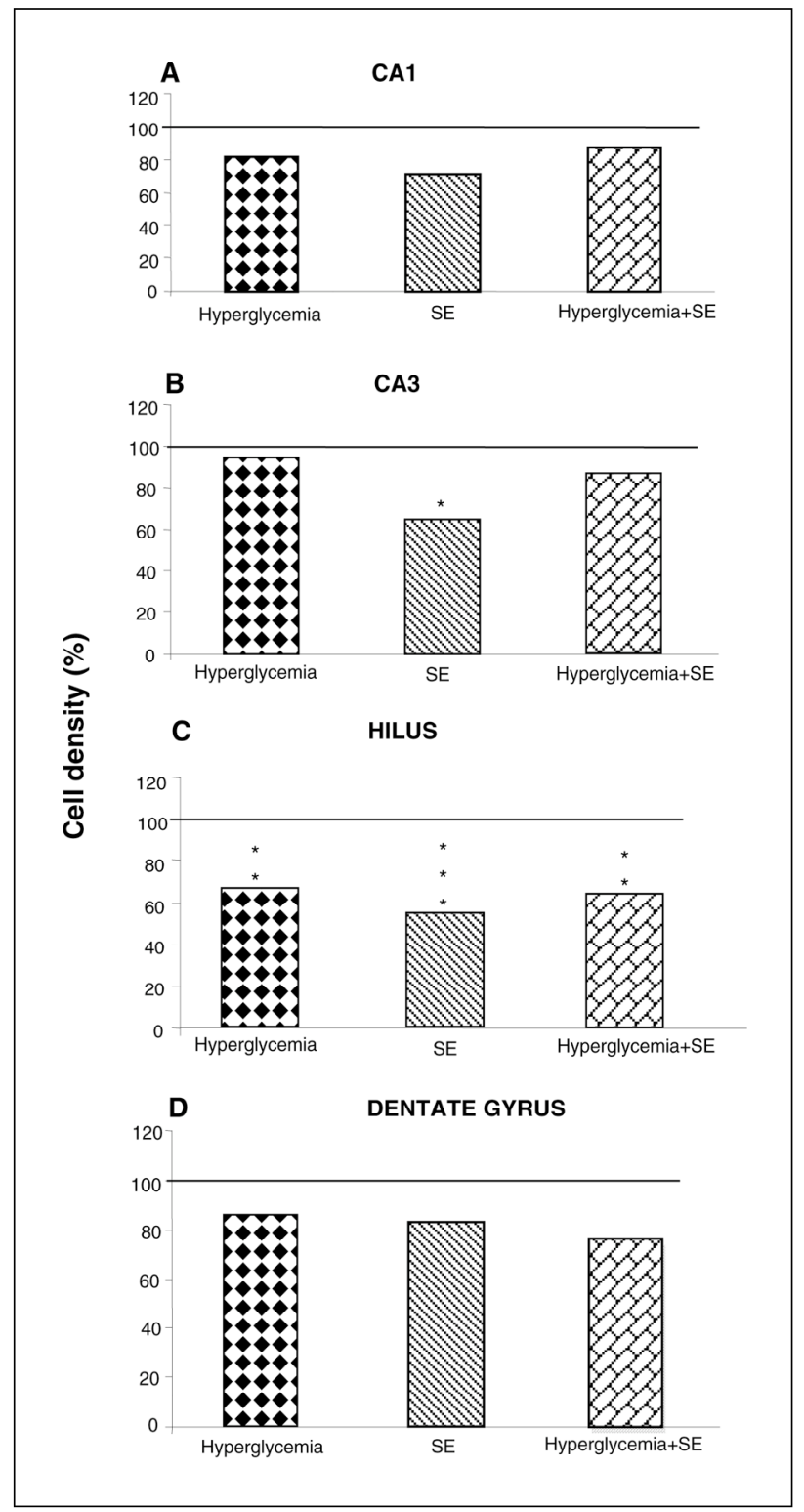

Fig 4. Number of neurons reimaining of GLUT3 immunostain ing in the hippocampal formation. Hyperglycemia-animals sub mitted to hyperglycemia, SE-animals submitted to SE Hyper glycemia+SE- animals submitted to SE plus hypeglycemia. A) CA1 region, B) CA3 region, C) dentate gyrus hilus region, $D$ ) dentate gyrus region. Groups $(n=8)$ of male Wistar rats with nine days of life (P9). The data are expressed as percentage of saline group. ANOVA followed by TUKEY-KRAMER test $(* p<0,05)$ $(* * p<0,01)(* * * p<0,001)$.

hyperdycemia showed cell death only in hilus region, showing that the high glucose blood level protect neurons from CA3 region (Fig 4).

\section{DISCUSSION}

To analyze the impact of a brain injury we should consider the age of the subject. The same type of aggression can cause different damage degree in the 
brain, depending on the stage of maturation of the nervous system. One, between several differences found in adults and developing animals is the rate of glucose consumption. The brain of newborn animals consumes $20 \%$ less glucose than adult brain ${ }^{11}$. In previous study done by our group we found that adult rats, submitted to long lasting SE showed hyperglycemia during the first $3 \mathrm{~h}$ of pilocarpine-induced $\mathrm{SE}$. This hyperglycemia may facilitate the entrance of glucose in the brain and could be involved in cell death during $\mathrm{SE}$.

Since developing animals presented normal blood glucose level and less cell death after induced-SE a question appears "could the increased glucose level in the brain intensify the cell death due to long-lasting SE". In this context, a group of P9 rats was submitted to SE plus hyperglycemia. Our results showed that only the hyperglycemia is able to kill neurons, mainly in hilus region. In contrast, animals presenting SE plus hyperglycemia presented less cell death in CA3 region, showing that the increased level of glucose in the brain can protect neurons from this specific region. These data are in agreement with those re ported by several authors ${ }^{12,13}$, who described a neuroprotector function of glucose during ischemia, in developing animals. Other works also re p ort that hyperdycemia protects cerebral ischemia, increasing the survival of animals submitted to hypoxia or anox$\mathrm{ia}^{14,15}$.

During SE, occurs hypermetabolism in the brain, $p$ romoted by intense neuronal activity ${ }^{8}$. In this context, high amount of glutamate is released, activating receptors related to sodium and calcium entrance. The cell edema, associated to increased activity of p roteases, nucleases and lipases may kill the cell by excitotoxicity ${ }^{16}$. With high glucose levels in the brain the amount of ATP can increase, facilitating all ATPdependent brain reaction, which could support the neurop rotection found in animals, submitted to SE plus hyperglycemia. However, a conflicting data is also reported in this work, which is related to cell death, found in the hippocampus of animals only submitted to hyperglycemia. More study should be done to understand this phenomenon.

P17 animals showed hypoglycemia, during the first hours of SE. Probably, in these animals the brain glucose consumption is greater, resulting in a plasmatic reduction in this carbohydrate. Older animals (P21) already presented hyperglycemia during the first hours of $S E$, resembling the data found in adult animals. However, we do not know if the hyperglycemia occurs due to a direct action of the pilocarpine on pancreatic cells, modifying insulin release and/or if the SE acting over the hypothalamic nucleus would be able to modify this hormone secretion.

Concerning to the expression of GLUT3 by animals from group I we found increased levels of this glucose transporter in animals presenting $\mathrm{SE}$, hyperglycemia and in those presenting SE plus hyperglycemia. These data showed increased metabolic rate and high glucose consumption in condition of SE and hyperglycemia, which is exacerbated when the SE is associated with hyperglycemia. These data are in accordance with previous reports ${ }^{17-19}$ and show important finding concerning to the function of glucose metabolism during $\mathrm{SE}$, in animals during development.

Acknowledgements - Thanks to Hilda da Silva Reis.

\section{REFERENCES}

1. Cavalheiro EA, Leite JP, Bortolotto ZA, Turski WA, Ikonomidou C, Turski L. Long-term effects of pilocarpine in rats: structural damage of the brain triggers kindling and spontaneous recurrent seizures. Epilepsia 1991;32:778-782.

2. Mello LE, Cavalheiro EA, Tan AM, et al. Circuit mechanism of seizures in the pilocarpine model of chronic epilepsy: cell loss and mossy fiber sprouting. Epilepsia 1993;34:985-995.

3. CavalheiroEA, Santos NF, Priel MR. The pilocarpine model of epilepsy in mice. Epilepsia 1996;37:1015-1019.

4. Priel MR, Santos NF, Cavalheiro EA. Developmental aspects of the pilocarpine model of epilepsy. Epilepsy Res 1996;26:115-121.

5. Santos NF, Arida RM, Filho EM, Priel MR, Cavalheiro EA. Epileptogenesis in immature rats following recurrent status epilepticus. Brain Res Rev 2000;32:269-276.

6. Kubova H, Mares P, Suchomelová L, Brozek G, Druga R, Pitkänen A. Status epilepticus in immature rats leads to behavioral and cognitive impairment and epiloptogenesis. Eur J Neurosci 2004;19:3255-3265.

7. Racine RJ. Modification of seizures activity by electrical stimulation: I. After-discharge threshold. Electroencephalogr Clin Neurophysiol 1972; 32:281-294

8. Fernandes MJS, Dubé C, Boyet S, Marescaux C, Nehlig A. Correlation between hypermetabolism and neuronal damage during status epilepticus induced by lithium and pilocarpine in immature and adult rats. J Cerebrovasc Blood Flow Metab 1999;19:195-209.

9. CavalheiroEA,Silva DF, Turski WA, Filho LSC, Bortolotto ZA, Turski L. The susceptibility of rats to pilocarpine-induced seizures is agedependent. Develop Brain Res 1987;37:43-58.

10. Reeves I, Mujsce D, Vannucci RC. Extreme hyperglycemia protects the perinatal brain from hypoxic-ischemic damage. Pedriatr Res 1992; 31:352A.

11. Vannucci SJ. Developmental expression of GLUT1 and GLUT3 glucose transporters in brain. J Neurochem 1994;62:240-246.

12. Hattori H, Wasterlain CG. Posthypoxic glucose supplement reduces hypoxic ischemic brain damage in the neonatal rat. Ann Neurol 1990; 28:122-128.

13. Vannucci RC, Vannucci SJ. Glucose metabolism in the developing brain. Semin Perinatol 2000;24:107-115.

14. SttafordA, Weatherall JAC. The survival of young rats in nitrogen. J Physiol 1960;153:457-472.

15. Voorhies TM, Rawlinson D, Vannucci RC. Glucose and perinatal hypoxic ischemic brain damage in the rat. Neurology 1986;36:1115-1118.

16. Berger R, Garnier Y. Pathophysiology of perinatal brain damage. Brain Res Rev 1999; 30:107-134.

17. Boileau P, Mrejen C, Girard J, Hauguel MS. Overexpression of GLUT3 placental glucose transporter in diabetic rats. J Clin Invest 1995;1: 309-317.

18. Khan JY, Rajakumar RA, Mcknight RA, Devaskar UP, Devaskar SU. Developmental regulation of genes mediating murine brain glucose uptake. Am J Physiol 1999;276:R892-R900.

19. Anderson MS, Ziegler JF, Das UG, Hay WW JR, Devaskar SU. Glucose transporter protein responses to selective hyperglycemia or hyperinsulinemia in fetal sheeep. AJP Regulat Integrat Comp Physiol 2001; 281,5;R1545-R1552. 